\title{
Designing User-Centered IoT Middleware Solutions for Small and Mid-Scale Farmers for Precision Agriculture using Cloud Computing
}

\author{
Nallusamy $\mathbf{C}^{1}$, Dr. G.Rajeshkumar ${ }^{2}$, Dr.S.Sadesh ${ }^{3}$, Arokia Jesu Prabhu L ${ }^{4}$, B.Manjubashini ${ }^{5}$ \\ ${ }^{1}$ Department of Information Technology, K.S.Rangasamy College of Technology, Tiruchengode,
}

Tamil Nadu, India. nallu80@yahoo.com

${ }^{2}$ Associate Professor, Department of Information Technology, Karpagam College of Engineering (Autonomous),

Othakkalmandapam, Coimbatore-641 032, Tamil Nadu, India, grajesh.grk@ gmail.com

${ }^{3}$ Associate Professor, Department of Information Technology, Velalar College of Engineering Technology,

Thindal, Erode. 638 012, Tamil Nadu, India, sadeshcse.velalar@ gmail.com

${ }^{4}$ Department of Computer Science and Engineering, Sri Sakthi Institute of Engineering and Technology, Coimbatore,

Tamil Nadu, India, arokiajeruprabhu@ gmail.com.

${ }^{5}$ Assistant Professor, Department of Computer Science and Engineering, Mahendra Institute of Technology, Namakkal,

Tamil Nadu, India, manjubabu16kavitha@gmail.com

\begin{abstract}
Agriculturists need an improved knowledge of farm characteristics and crop development to overcome the variability that is one of the main problems for agricultural productivity. The recent growth in the Internet of Things provides a world in which real objects with limited capacity can capture data from the sensors and share the information with the Internet, thereby creating a global network of sensed data. Existing solutions rely on tremendous investment in infrastructure equipment and field-design changes, making them unworkable for less mechanized farms. Modern agriculture relies on farming models that assist in predicting returns and costs that include data on worker behavior as well. The program proposes to control irrigation in agriculture through an integrated Agri-IoTBased Smart Irrigation System (IBSIS). Based upon both soil tests and climatic changes collected by various independent threads in the field, our system analyzed the weekly irrigation requirements for a farm. Our approach is to use a conventional Smartphone integrated with sensors are used to monitor the position and motion of workers to enable the inference of activity.
\end{abstract}

Key words: Precision Agriculture, Sensors, Internet of Things, Cloud Computing, Smart Phone, Smart Irrigation System.

\section{INTRODUCTION}

The food supply will significantly rise, with new techniques designed to create more efficient methods of agricultural production, in order to accommodate a broader population [1]. India is a mostly agricultural nation with essential repercussions for food and nutrition security as well. Therefore, we must develop ways to produce more production using limited natural resources in order to address the challenges of food production [2]. Agriculturists need an improved knowledge of farm characteristics and crop development to overcome the variability that is one of the main problems for agricultural productivity. Precision Agriculture plans to reinforce the collection of farming data by collecting data in each phase of the production process, from planning to end product. In addition, smart agriculture software can integrate farmers in decision-making and resource management by incorporating various information sources such as sensors, satellite communication, and weather forecasts [3]. Figure 1 provides an overview of a typical agricultural precision model that integrates communication infrastructures between Things devices' Internet. The research work into less cost, smaller, energy-efficient network nodes has enabled wireless nodes to be used both on the ground and attached to the final product.

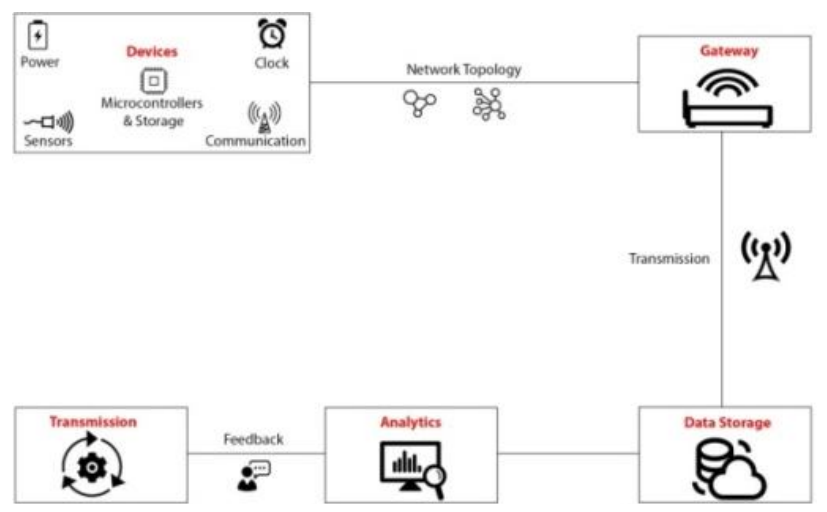

Figure 1: Precision Agriculture System overview IoT 
In order to achieve their objectives, farmers have introduced these new information systems in their farms. Traditional methods used for farmers are becoming redundant and ineffective [4]. Some farmers' issues may be mitigated by ICT. Now we are heading to the third and potentially most distracting "stage of the Internet review the "Internet of Things" (IoT), which is also known as "Ubiquitous Computing" - after the World Wide Web and the mobile Internet of the 2020s [5]. Reliable farming equipment with WLANs can take account of crop conditions and adjust how each part of a field is cultivated-for instance, by supplying additional fertilizer to areas that need other nutrients. For large-scale farms, technology has been developed to deal with the problem of computerized data acquisition through the use, by using Global Positioning System (GPS) [6] (figure 2), radar data, and intelligent systems. Solutions are available in this type of cultivation to map data on the task in space/time, such as crop yield or volume of fertilizer used, between performed tasks.

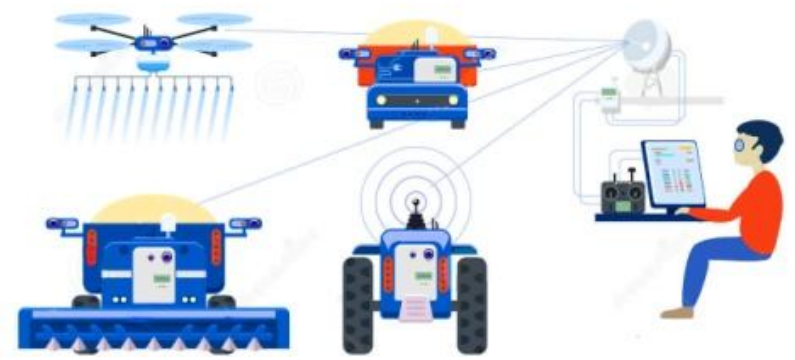

Figure 2: Accuracy seeding in the machine with GPS support

This article presents an overview of how human-centered design is implemented to effectively fix the world agricultural production crisis by integrating user feedback into the IoT solution's agile development and designing. The system must be able to monitor the path traced with an adequate margin of error on the crop in order to generate value for farmers. For example, the system should be able to evaluate on the fruit-tree's side, which of the fruit-tree the agent is present at any given time. In an application that aims at capturing productivity metrics, the solution must not impact the worker's performance in the production process. In order to monitor everyone who works on a farm without their performance and comfort being changed, the system must thus be adapted to various human populations.

\section{LITERATURE REVIEW}

Irrigation refers to the artificial supply of water to support cultivated plants and represents the majority of water drainage. Farmers often add crop irrigation to the natural pluvial rainfall. Eight common types of irrigation systems are defined by the Center for Disease Control (CDC) [7] based on water distribution throughout the field: irrigation surface water, located water irrigation, etc. Due to its high water storage to water application ratio, the drop irrigation of these different irrigation methods achieves the highest average efficiency of application (90.16\%). By comparison, the average user efficiency of surface irrigation is $65.17 \%$, and the ability of the sprinklers is $78.19 \%$.

The simultaneous measurement of a more significant number of variables is becoming more comfortable and more ubiquitous. The problem of practical learning from a limited training set is, therefore, becoming more and more critical. As a recent classification approach, Supporting Vector Machines (SVMs) [8] addresses this problem in machine learning techniques. They implement adjustable flexibility identifications optimized on the training samples on an excellent performance automatically and in principle way [9].

The researcher demonstrates the effectiveness of a fine seed irrigation system using a WSN in order to more accurately irrigate the field by using only water when this is necessary. Data on soil and atmospheric parameters such as humidity, temperature, and humidity are required when using this irrigation method. With distance, data rate, compatibility and costs in mind, it was decided, by Zig Bee and another license less radio frequency transmission protocols, to use the Bluetooth protocol to carry out communication between the sensing stations and the machines of the base station [10].

It provides terminals with location or location determination and time information about the planet Earth, even in weather conditions. GPS is a Global Navigation Satellite System (GNSS) [11]. Since 2011, there are other worldwide navigation satellites like Russian GLONASS. In addition, some GPS recipients can use the GLONASS constellation and become more accurate through both systems. Europe and China also deploy their fully operational navigation systems by 2020 [12].

A distribution map with soil humidity substance tests taken at nine sites in the preferred agricultural area was created using the IoT-based Wireless Sensor Network (WSN). In order to water crops using a wireless sensor network, an IoT-based method was developed, and a web application was also designed to monitor crop and field information. Most of the algorithms used to predict and predict machines have been used. A new model for predicting water levels in the Winnipesaukee and Cypress Lakes, USA, was developed utilizing a combination of the gravitational research algorithm with Multilayer Perception (MLP) [13]. In a particular search engine ranking, a neural network form was suggested by using MLP to forecast the offer cost of the keyword.

In order to optimize water and energy consumption, a Fuzzy Decision Tree System was proposed. In addition, this was done with the help of the Internet. In addition, several soil parameters should be considered to help farmers to save natural resources and the environment, 
which decline day by day. In addition, factors such as soil humidity and the temperature of the earth were used to measure water requirements for making appropriate decisions on the release of the water [14]. For the control of overall configuration, cloud-based IoT sensors are helpful. This saves energy in turn [15] [16].

\section{MATERIALS AND METHODS}

\subsection{Questions and Goals of Research}

The main aim of this investigation is to gain knowledge of the parameters which affect the implementation in India of Agri-IoT agriculture [17] [18] [19]. The rapidly developing Agri-IBSIS industry has multifaceted and is expected to be both complex and globalized in the agricultural sector in order to advance and delay its implementation. For this research, minor areas of interest are:

- Investigate the current Agri-IBSIS technology available to Indian farmers [20].

- Intellect and approach of Indian farmers to Agri-IBSIS

- Focus groups were conducted on how to maximize economic benefit for Indian agriculture from this modern innovation.

\subsection{Technologies for precision farming}

It is also essential to investigate technologies that collect data from all stages of the agricultural process in a clear perspective of modern agricultural models [21] [22]. There are data collection processes that reach the level of individual plants using Field sensors in some precision agriculture systems that are applied to heavily highly automated crops. Such methods, combined with large farms, can produce enormous quantities of data to be analyzed and made available as information. In order to optimize their crop production, farmers may then change the parameters affecting a given area in the field, such as soil humidité, nutrients, or pesticides. The impact on radio signals affecting the system's overall availability and performance of plant canopy and other natural barriers to the agricultural sector is an essential problem in developing such systems.

Figure 3 describes this system and describes the IBSIS used in precision agriculture. The remote server saves all the details, provides a graphical application that allows the monitoring of sensor data and the programming of irrigation systems [23][24]. In comparison with a conventional water irrigation system in the experiments, $60.16 \%$ and $90.19 \%$ of the sage crop were achieved by the implementation of the above-described method. The aim is to reduce the cost of automatic irrigation planning with components outside of the shelf while still attempting to improve irrigation effectiveness.

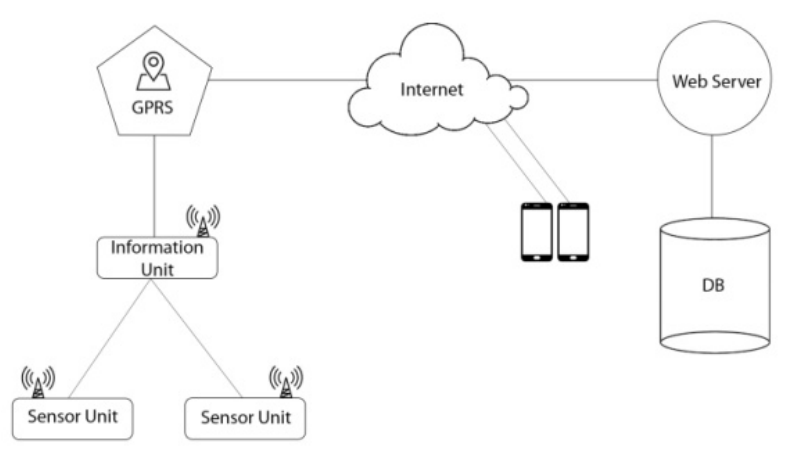

Figure 3: Unit description of the WSN and GPRS automatic irrigation network

The researchers also used RFID tags to transfer data to the central node in order to achieve the reference objective. Other changes require the use of radiofrequency licenses when using the transmission of RFID tags, and licensing is not necessary at $2.5 \mathrm{GHz}$, which results in a significant reduction [25] [26] [27]. In order to prevent a signal diminution, the surrounding plants strongly impacted the wireless transmissions and had to be positioned over the top of the plants. The intelligent sensor boards have been powered by a $12 \mathrm{~V}$ battery that can deliver power throughout the growing season, and perform measured sensor results and data transmission every hour during this time [28] [29][30].

\subsubsection{Agri-IBSIS Model Algorithm}

The following Algorithm 1 explains how the data obtained from the different sensors will be processed. As the data size is quite large, the data must be handled using the algorithm that can handle the expected data size. That is why a neural network method for data processing is measured here [31][32][33]. Further information is provided below about the algorithm presented here.

\section{Algorithm 1 for IBSIS Model}

1: Assign the weights $\mathrm{W}_{\mathrm{i}}$ ) to small random numbers, Bias

2: While (stopping criteria not met) Do

3: For every pattern of preparation $\left(\mathrm{P}_{\mathrm{i}}, \mathrm{Q}_{\mathrm{i}}\right)$ Do

4: Advance the entry process:

5: Enable any entry: $\mathrm{P}_{\mathrm{i}}=\mathrm{S}_{\mathrm{i}}, \mathrm{i} \in 1$ to $\mathrm{N}$

6: Input net: $\mathrm{Q}_{\mathrm{i}}=\mathrm{B}_{\mathrm{i}}+\sum \mathrm{N}_{\mathrm{i}}=1 \mathrm{P}_{\mathrm{i}} \cdot \mathrm{W}_{\mathrm{i}}$

7: where $\mathrm{Bi}=$ bias, $\mathrm{N}=$ No. of neurons, $\mathrm{Q}-$ Actual $\mathrm{o} / \mathrm{p}$,

8: Expected outcome with activation function:

9; $\mathrm{fQ}_{\text {In }}=1$ If $\mathrm{Q}_{\text {In }}>\theta 0$ if $-\theta \leq \mathrm{Q}_{\text {In }} \leq \theta-1$ if $\mathrm{Q}_{\text {In }}<-\theta$

10: Adjust weight and bias:

11: If $\mathrm{Q} \neq \mathrm{T}$,

12: $\mathrm{W}_{\mathrm{i}}($ new $)=\mathrm{Wi}($ old $)+\propto \mathrm{TP}_{\mathrm{i}}$

13: $\mathrm{B}_{\mathrm{i}}($ new $)=\mathrm{B}_{\mathrm{i}}($ old $)+\propto \mathrm{T}$

14: If $\mathrm{Q}=\mathrm{T}$, 
15: $\mathrm{W}_{\mathrm{i}}($ new $)=\mathrm{W}_{\mathrm{i}}($ old $)$

16: $\mathrm{B}_{\mathrm{i}}($ new $)=\mathrm{B}_{\mathrm{i}}($ old $)$

17: Average gradient computation:

18. Each error's gradient calculation as regards $\mathrm{w}_{\mathrm{i}}$

19: $\mathrm{E}(\mathrm{W})=12 \sum \mathrm{i} \sum \mathrm{K} \in \mathrm{Q}\left(\mathrm{T}_{\mathrm{i}} \mathrm{k}-\mathrm{Q}_{\mathrm{i}} \mathrm{K}\right) 2$

20: Where, $\mathrm{T}_{\mathrm{i}} \mathrm{K}, \mathrm{Q}_{\mathrm{i}} \mathrm{K}$ is the goal and the actual o/p at the $\mathrm{i} / \mathrm{p}$

21: End

22: The hidden layer is computed

23: End

\section{PERFORMANCE OF IOT BASED SMART IRRIGATION SYSTEM (IBSIS)}

\subsection{Dataset and study field description}

Data from the unique rural areas of the district of Salem in the State of Tamil Nadu, India are collected for this assessment. We have identified a range of limits that influence crop yields with expert opinions [34][35]. This dataset collection combines distinguishing climatic, soil, and underground water properties. Four decision classes, namely most appropriate, suitable, moderately suitable, and unsuitable, are considered here for land adequacy assessment[36][37][38].

\subsection{Measures of Performance}

For multi-class classification, the performance parameters evaluated are described as follows. For a class ' $C$,' the efficiency and performance of clinically determined sample counts can be assessed as True Positive (TP), True Negative (TN), False Positive (FP), and False Negative (FN) [39][40]. Different performance methodologies for the evaluation of IBSIS are calculated for problems of multi-class classification. By define the no. of correct predictions made from all assumptions, classification exactness analyses could be used to find out the accuracy of the model. This also allows us to assess the efficiency of the model per class and is computed as EQU (1).

$$
\text { Accuracy }=\frac{T P+T N}{(T P+T N)+(F P+F N)}
$$

For the multi-layer classification setting, the performance metrics such as Precision, Recall, F1 score, etc. must be generalized. We compute the micro and macro-average to meet the ability to adhere. The performance is evaluated with the micro-averaging, i.e., Precision, Recall, and F1 score from each model n-class TP, TN, FP, and FN.

\subsection{Factors for Agri-IBSIS Adoption}

Performance expectancy was one of the strongest motivators of the Agri-IBSIS model for technology adoption. This is defined as the extent to which the system helps an individual to achieve situation performance. Agri-
IBSIS users were asked to recognize their Agri-IBSIS use experience, which is known as condition-based, as three main advantages on the ground. Non-users have been asked to include, as a performance expectation, what they perceive to be the top three advantages of Agri-IBSIS. The percentages of all farmers who gave this category a lead are included in figure 4.

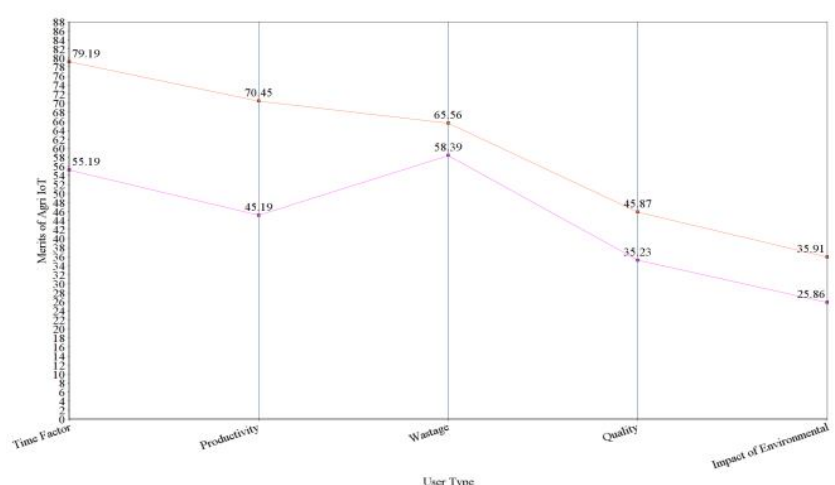

Figure 4: User V Non-User Agri-IBSIS Demerits

The two significant advantages of Agri-IBSIS were sparing time and increasing productivity by working users, with an $80.16 \%$ benefit saved by farmers listing time with an increase in productivity as well as $72.19 \%$. In general, the richness of Agri-IBSIS is expected to be much lower by non-users in all classes. In two categories, the performance experience and performance expectations are separated. More than $70.19 \%$ of users regard productivity increases as an advantage of Agri-IBSIS devices, while only $35.19 \%$ of non-users expect that. Likewise, $37.19 \%$ of users have a power of improved quality, while $12.31 \%$ of non-users expect this to be a benefit. It is also clear that informed farmers have a significant barrier to the use of modern innovation, with $27.90 \%$ of those who do not know what the benefits of such a technology would be.

\subsection{Effort Expect-ability v Experience}

Effort expectation is the following key reason to adopt the technology outlined in the Agri-IBSIS model. The three most important disadvantages of Agri-IBSIS's user experiences were asked to identify; this can be considered effort experience. For non-users, what they find the top three problems of Agri-IBSIS use are requested to be listed as expected effort (figure 5). 


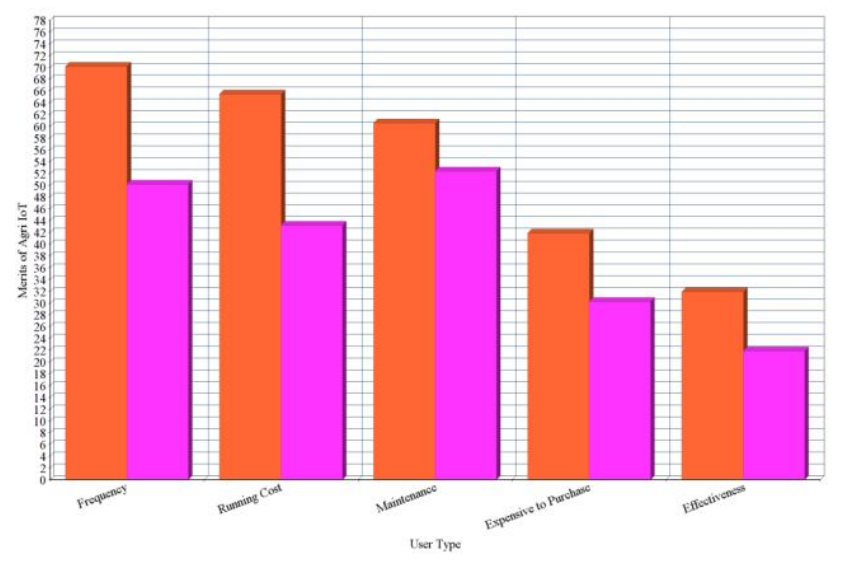

Figure 5: User V Non-User Agri-IBSIS Disadvantages

'Actual Cost' was the main drawback of both users and nonusers, with $66.19 \%$ of users, and $54.15 \%$ of non-users register this as a weakness. The expected and experienced effort to preserve Agri-IBSIS systems is jointly co-ordinated by a considerable $40.19 \%$ of active users, with the disadvantage of highlighting the need for simpler and more robust Agri-IBSIS systems, but also for farmer training on how to operate and maintain this new technology[24]. High running costs are predicted to be a drawback for non-users to a better extent than those reviewed by actual users, indicating a perceived barrier that may not be as problematic as thought. A large number of active users are disappointed that their Agri-IBSIS system is not as valuable as hoped, due to the arrangement of equipment hype, recently developed immature platforms and the sale of system capabilities by sales teams. When non-users were explicitly asked why they had not yet purchased the Agri-IBSIS device, the most significant reply was to cite a lack of technical information, after those nonusers indicated that they did not need such a system, but also waited for it to improve [25] [41].

\section{MONITORING WORKER'S LOCATION}

\subsection{Assessment of location}

A Smartphone and its sensors are being used to detect the positioning of the worker on a working day to solve the problem of agricultural workforce control to meet the requirements outlined in Section 5.1 with this analysis, and we intend to assess the capacity of the current Smartphone built-in sensor to capture reliable location data in adverse environments such as agricultural fields. GPS has high power requirements, and energy is a scarce resource in rural areas. The aim was to evaluate the error introduced with these solutions and quantify it from the perspective of later combining the two navigation solutions-GPS+Dead Reckoning. In addition to GPS and Navigation technologies, there are other potential mechanisms to be included in the final solution, such as the Cell Tower and Bluetooth Beacon triangulations. However, cell towers are far apart in rural areas, and the accuracy drops significantly. The other solution is to create a wireless beacon mesh in the field of agriculture and to use the same triangulation principle to measure beacon signals.

\subsection{Dead Reckoning}

The first stage requires the user to take an already known distance and to calibrate the algorithm for the average step length of the employee by counting the number of steps that they are taking. The application uses data from an accelerometer to detect new user steps in order to understand this value. The process of step-recognition begins with the search for maximum amplitude peaks. The acceleration magnitude is calculated, EQU (2), where we search in $355 \mathrm{~m}$ (Figure 6) for peaks above $13 \mathrm{~m} / \mathrm{s} 2$.

$$
|A c c|=\sqrt{A c c_{x}^{2}+A c c_{y}^{2}+A c c_{z}^{2}}
$$

Ubejd Shala et al. [33] indicate that a typical human step creates a peak of $13 \mathrm{~m} / \mathrm{s} 2$ on average. We set a threshold of $13 \mathrm{~m} / \mathrm{s} 2$ for small worker movements. We have taken this into account. In a $355 \mathrm{~ms}$ timeframe, only one step is made when two or more consecutive steps occur. This presupposes that while a regular person walks a step in this period cannot take two steps, which correspond to incorrect detections in which one step produces two peaks. An example of the two consecutive steps acceleration readings is shown in Figure 7. The new co-ordinates must be calculated when a new phase is detected. The average step distance of the farmer, the azimuth angle, and the early coordinate can be used according to the following equations in this process:

In the globe, co-ordinates system $\mathrm{X}$ and $\mathrm{Y}$ represent the position of the worker; $\mathrm{D}$ represents the distance between $\mathrm{T}-1$ and $\mathrm{T}$; $\alpha$ represents the corner of the azimuth, and $\mathrm{O}_{\mathrm{T}}$ represents the orientation of the field.

$$
\begin{aligned}
X_{T} & =X_{T-1}+D\left(\alpha-O_{T}+\Pi\right) \ldots \ldots .(3) \\
Y_{T} & =Y_{T-1}+D\left(\alpha-O_{T}+\Pi\right) \ldots \ldots . .(4)
\end{aligned}
$$
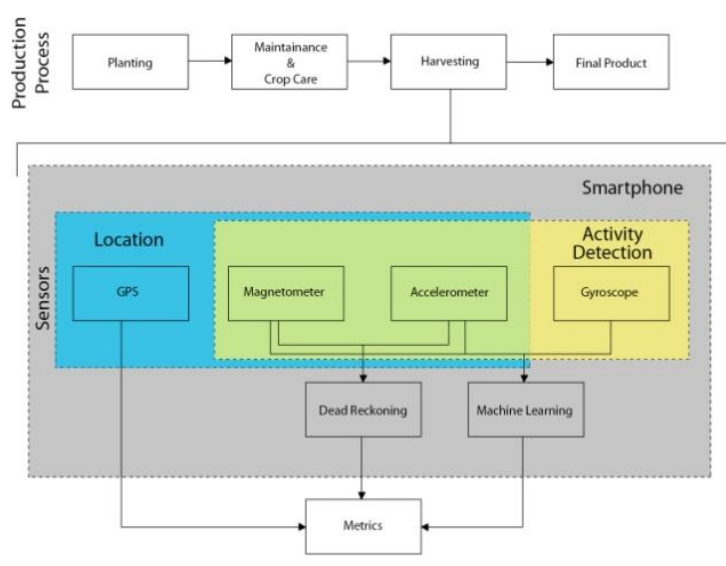

Figure 6: The Harvesting Process System Architecture 
The Android OS gives a get orientation function that takes the input of accelerometer and magnetometer data and calculates a vector with anticlockwise angles around each axis of the device.

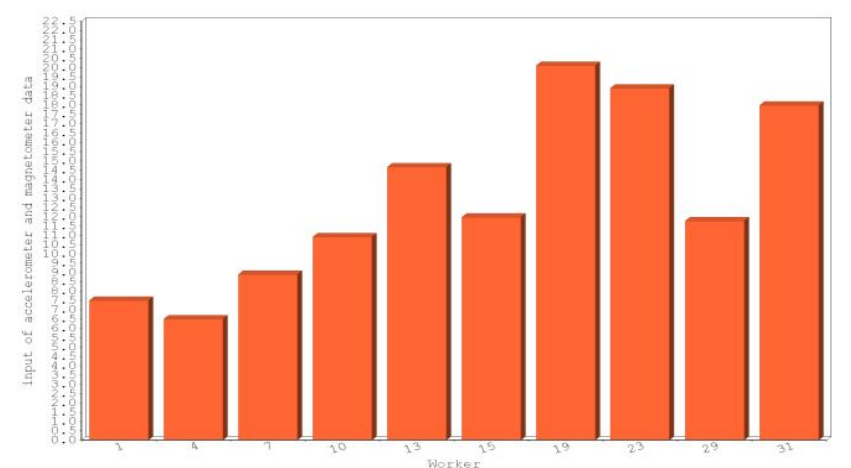

Figure 7: Global Acceleration of two consecutive steps

\section{CONCLUSIONS}

Farmers desire to have more in-depth control over the quality of their products, and the agricultural business is developing with an emphasis on productivity and efficiency. This resulted in the establishment of agrarian production models using farm data to reduce costs and maximize productivity while forecasting farm enterprises' future. For this study, user research focused on a group of self-select lawyers in India with a tendency to embrace new technologies. We introduced an agricultural worker monitoring system which can recognize work in a rural atmosphere in order to enhance the knowledge of farmers on their farms.

Our method helps to monitor farming processes by means of a Smartphone next to the working lumbar area with a belt to any farmer with a particular crop farm. GPS and Dead Reckoning were used by our solution. GPS is the widely-used navigation technology and appliances for farm systems, but we must consider the presence of trees that attenuate signal reception when considering fruit orchards. Dead calculation systems do not depend on external data to work but need a known starting point in order to provide absolute co-ordinates and have error accumulation problems as well. Comparing the two solutions, we discovered that dead calculations are new precise and that trees are no problem when compared to the solution based on GPS.

\section{REFERENCES}

1. Willig and H.Karl, Protocols and the Architectures for Wireless Sensor Networks, John Wiley and Sons Ltd, The Atrium, Southern Gate, Chichester, West Sussex, England, 2005.

2. Brewster, C. et al. IoT in Agriculture: Designing a Europe-Wide Large-Scale Pilot, IEEE Communications Magazine 55(9): 26-33, 2017.
3. Doyle, L. Using the Internet of things to predict the future of flooding in Dublin, from http://www.engineersjournal.ie/2017/07/18/usinginternet-things-predict-future-flooding-dublin/, 2017.

4. Kamilaris, A. Agri-IoT: A semantic framework for Internet of Things-enabled smart farming applications. 2016 IEEE 3rd World Forum on Internet of Things (WF-IoT).

5. Luvisi, E. Triolo, E. Rinaldelli, R. Bandinelli, M. Pagano, and B. Gini, Radiofrequency applications in grapevine: From vineyard to web, Computers, and Electronics in Agriculture, vol. 70, no. 1, pp. 256-259, 2010.

6. M.Noor, Z.Salcic and K.I.Wang, Dynamic sliding window method for physical activity recognition using a single tri-axial accelerometer, in Industrial Electronics and Applications (ICIEA), 2015 IEEE 10th Conference on, pp. 102-107, IEEE, 2015.

7. Y.Gu and T.Jing, The IoT research in supply chain management of fresh agricultural products, 2011 2nd International Conference on Artificial Intelligence, Management Science, and Electroni. Commerce, AIMSEC 2011- Proceedings, pp. 73827385, 2011.

8. S.R.Rupanagudi, P.Nagaraj, and V.G.Bhat, A novel cloud computing-based smart farming system for early detection of borer insects in tomatoes, in 2015 International Conference on Communication, Information \& Computing Technology (ICCICT), pp. 1-6, IEEE, Jan 2015.

9. J.O.Ferreira, M.O.Batalha, and J.C.Domingos, Integrated planning model for citrus agribusiness system using systems dynamics, Computers, and Electronics in Agriculture, vol. 126, pp. 1-11, 2016.

10. L. Ruiz-Garcia, L. Lunadei, P. Barreiro, and I. Robla, A Review of Wireless Sensor Technologies and Applications in Agriculture and Food Industry: State of the Art and Current Trends, Sensors, vol. 9, no. 6, pp. 4728-4750, 2009.

11. J.Hwang, J.Kang, Y.Jang, and H.Kim, Development of novel algorithm and real-time monitoring ambulatory system using Blue Tooth module for fall detection in the elderly, in Engineering in Medicine and Biology Society, EMBS'04. 26th Annual International Conference of the IEEE, vol. 1, pp. 2204-2207, IEEE, 2004.

12. N.Kalatzis K.Doolin C.Brewster I.Roussaki and K.Ellis, IoT in Agriculture: Designing a EuropeWide Large-Scale Pilot, In IEEE (Sept. 2017). DOI 10.1109/MCOM.2017.1600528.

13. Charumathi M C Dr. M Suchithra Asuwini T and Ritu $\mathrm{N}$ Lal, Monitoring Of Agricultural Crops Using Cloud and IoT with Sensor Data Validation, In International Journal of Pure and Applied Mathematics 119.12 (2018). ISSN: 1314-3395.

14. J.Won X.Jin R.Chandra A.Kapoor S.N.Sinha D.Vasisht Z.Kapetanovic and M.Sudarshan. FarmBeats: An IoT Platform for Data-Driven 
Agriculture, In usenix - The advantaged computing systems association (2017). ISBN 978-1-931971-37-9.

15. S.Sudhakar, V.Vijayakumar, C.SathiyaKumar, V.Priya, Logesh Ravi, V.Subramaniyaswamy, Unmanned Aerial Vehicle (UAV) based Forest Fire Detection and monitoring for reducing false alarms in forestfires, Elsevier-Computer Communications 149, 1-16, https://doi.org/10.1016/j.comcom.2019.10.007,2020

16. S.Sudhakar, N.Satheesh, S.Balu, Amireddy Srinish Reddy, G.Murugan, Optimizing Joins in a MapReduce for Data Storage and Retrieval Performance Analysis of Query Processing in HDFS for Big Data, International Journal of Advanced Trends in Computer Science and Engineering, (IJATCSE), Vol.8, No 5, pp: 2062-2067, DOI: 10.30534/ijatcse/2019/33852019.

17. Avuthu Sai Meghana, Sudhakar S, Arumugam G, Srinivasan P, Kolla Bhanu Prakash, Age and Gender prediction using Convolution, ResNet50, and Inception ResNetV2, International Journal of Advanced Trends in Computer Science and Engineering, Vol..9, Issue.2, March-April 2020, pp: 1328-1334

https://doi.org/10.30534/ijatcse/2020/65922020.

18. Yellapragada SS Bharadwaj, Rajaram P, Sriram V.P, Sudhakar S, Kolla Bhanu Prakash, Effective Handwritten Digit Recognition using Deep Convolution Neural Network, International Journal of Advanced Trends in Computer Science and Engineering, Vol..9, No.2,March-April:2020,pp:13351339,https://doi.org/10.30534/ijatcse/2020/66922020.

19. Donepudi Babitha, Jayasankar.T, Sriram V.P, Sudhakar S, Kolla Bhanu Prakash, Speech Emotion Recognition using State-of-Art Learning Algorithms, International Journal of Advanced Trends in Computer Science and Engineering, Vol.9, Issue.2, March-April 2020,PP:1340-

1345,https://doi.org/10.30534/ijatcse/2020/67922020.

20. Murugan G, Syed Musthafa A, Abdul Jaleel D, Sathiya Kumar C, Sudhakar S, Tourist Spot Proposal System Using Text Mining, International Journal of Advanced Trends in Computer Science and Engineering, Vol.9, Issue.2, March-April 2020, pp: 1358-1364, https://doi.org/10.30534/ijatcse/2020/70922020.

21. E.Punarselvam, Mohamed Yacin Sikkandar, Mohsen Bakouri, N.B.Prakash, T.Jayasankar, S. Sudhakar, Different loading condition and angle measurement of human lumbar spine MRI image using ANSYS, Journal of Ambient Intelligence and Humanized Computing, https://doi.org/10.1007/s12652-020-019397,11, 2020.

22. R.Vasanthi, R.Jayavadivel, K.Prasadh, J.Vellingiri, G.A kilarasu, S.Sudhakar, P.M.Balasubramaniam, A novel user interaction middleware component system for ubiquitous soft computing environment by using fuzzy agent computing system, Journal of Ambient Intelligence and Humanized Computing, Springer, doi.org/10.1007/s12652-020-01893-4,2020
23. Sudhakar Sengan, Subramaniyaswamy, V., Sreekumar Krishnan Nair, Indragandhi, V., Manikandan, J., Logesh Ravi, Enhancing cyber-physical systems with hybrid smart city cybersecurity architecture for secure public data-smart network, https://doi.org/10.1016/j.future.2020.06.028, Elsevier. Future Generation Computer Systems (2020).

24. Ganesh Kumar, K, and Sudhakar Sengan, Improved Network Traffic by Attacking Denial of Service to Protect Resource Using Z-Test Based 4-Tier Geomark Traceback (Z4TGT), Wireless Personal Communications, Springer. https://doi.org/10.1007/s11277-020-07546-1,2020.

25. Vijaya Kumar Veerabathiran, Devi Mani, Sangeetha Kuppusamy, Balu Subramaniam, Priya Velayutham, Sudhakar Sengan \& Sujatha Krishnamoorthy, Improving secured ID-based authentication for cloud computing through novel hybrid fuzzy-based homomorphic proxy re-encryption, Springer, Soft Computing, 2020, DOI 10.1007/s00500-020-05119-9.

26. M. Karthikeyan, K. Sharmilee, P.M. Balasubramaniam, N.B. Prakash, M. Rajesh Babu, V. Subramaniyaswamy, Sudhakar Sengan, Design and Implementation of ANN-based SAPF Approach for Current Harmonics Mitigation in Industrial Power Systems, DOI:10.1016/j.micpro.2020.103194, Elsevier, Microprocessors, and Microsystems (2020).

27. Sudhakar Sengan, Subramaniyaswamy, V., Sreekumar Krishnan Nair, Indragandhi, V., Manikandan, J., Logesh Ravi, Enhancing cyber-physical systems with hybrid smart city cybersecurity architecture for secure public data-smart network, DOI 10.1016/j.future.2020.06.028,Elsevier,Future Generation Computer Systems (2020).

28. N. Satheesh, P. Udayakumar, Sudhakar Sengan, Testing for IoT Devices and Software's and Effects of New Features on Security and Privacy by using Test Simulation, International Journal of Advanced Science and Technology, Vol. 29, No. 03, (2020), pp. 8715 - 8726.

29. A.Pushpalatha, D.Prabha, S.Sudhakar, V.P.Sriram, P.Kevin Mario Gerard, S.Sanjay, A Study Of Detecting Malicious URL Using Convnet, International Journal of Scientific \& Technology Research, Vol.9, Issue 04, April 2020.

30. Kanmani P, Priya V, Yuvaraj N, Sudhakar S, Sriram V $\mathrm{P}$, Inaccuracy Correction Method for Moving Shapes and Shadows in Video Coding Object, International Journal of Scientific \& Technology Research, Vol.9, Issue 03, March 2020, PP: 45614566.

31. Jagadeesh Gopal, Vellingiri J, Gitanjali J, Arivuselvan K, Sudhakar S, An Improved Trusted On-Demand Multicast Routing with QoS for Wireless Networks, International Journal of Advanced Trends in Computer Science and Engineering, Vol.9,No.1,January- 
February 2020, PP:261-265, https://doi.org/10.30534/ijatcse/2020/39912020.

32. R.Gowthamani, K.Sasi Kala Rani, E.Mohanraj, S.Sudhakar, Enhancing Security Through Blockchain Technology -A Quick Review, International Journal of Scientific \& Technology Research, Vol.9, Issue 02, February 2020, pp: 51265129.

33. S.Biruntha, S.Balaji, S.Dhyakesh, B.R.Karthik Srini, J.Boopala, S.Sudhakar, Digital Approach For Siddha Pulse Diagnosis, International Journal of Scientific \& Technology Research, Vol.9, Issue 02, February 2020, pp: 2140-2143.

34. P.Deivendran, K.Anbazhagan, P.Sailaja, E.Sujatha, M.Rajesh Babu, S.Sudhakar, Scalability Service In Data Center Persistent Storage Allocation Using Virtual Machines, International Journal of Scientific \& Technology Research, Vol.9, Issue 02, February 2020, pp: 2135-2139.

35. K.Devipriya, D.Prabha, V.Pirya, S.Sudhakar, Deep Learning Sentiment Analysis For Recommendations In Social Applications, International Journal of Scientific \& Technology Research, Vol.9, No.01, January 2020, pp: 3812-3815.

36. K.Sasi Kala Rani, D.Ramya, J.Manikandan, S.Sudhakar, Monitoring Emotions In The Classroom Using Machine Learning, International Journal of Scientific \& Technology Research, Vol.9, No. 01, January 2020, pp:3723-3726.

37. P.M.Balasubramaniam, S.Sudhakar, Sujatha Krishnamoorthy, V.P.Sriram, S.Dhanaraj, V.Subramaniyaswamy, Investigations, and Strategy of Intelligent Controller (ACBIC) for DC-Link control in SAPF system for Industrial power systems a control strategy, Journal of Discrete Mathematical Sciences \& Cryptography (Taylor \& Francis), (2020) https://doi.org/10.1080/09720529.2019.1668145.

38. P.M.Balasubramaniam, S.Sudhakar, Sujatha Krishnamoorthy, V.P.Sriram, S.Dhanaraj, V.Subramaniyaswamy, T.Rajesh "An efficient control strategy of shunt active power filter for asymmetrical load condition using time-domain approach," Journal of Discrete Mathematical Sciences \& Cryptography, (Taylor \& Francis) (2020), https://doi.org/10.1080/09720529.2019.1668136.

39. Satheesh N, Sudha D, Suganthi D, Sudhakar S, Dhanaraj S, Sriram VP, Priya V, "Certain improvements to Location aided packet marking and DDoS attacks in internet," Journal of Engineering Science and Technology, Vol.15, No.1 (2020), pp: 94-107.

40. Sathiya Kumar.C, Priya.V, Sriram.V.P, Sankar Ganesh.K, Murugan.G, Devi Mani, Sudhakar.S, "An Efficient Algorithm for Quantum Key distribution with Secure Communication, Journal of Engineering Science and Technology Vol. 15, No. 1 (2020), pp:7793.
41. S.Sudhakar, N.Satheesh, S.Balu, Amireddy Srinish Reddy, G.Murugan, 2019, Optimizing Joins in a Map-Reduce for Data Storage and Retrieval Performance Analysis of Query Processing in HDFS for Big Data, International Journal of Advanced Trends in Computer Science and Engineering, (IJATCSE), Vol.8, No 5, pp: 2062-2067, DOI: $10.30534 / \mathrm{ijatcse} / 2019 / 33852019$. 